\title{
Knowledge of pre-eclampsia and eclampsia in Bangladesh
}

Kanij Sultana

Population Council

Amy Dempsey

Population Council

Follow this and additional works at: https://knowledgecommons.popcouncil.org/departments_sbsr-rh

Part of the Demography, Population, and Ecology Commons, Family, Life Course, and Society Commons, International Public Health Commons, and the Maternal and Child Health Commons How does access to this work benefit you? Let us know!

\section{Recommended Citation}

Sultana, Kanij and Amy Dempsey. 2017. "Knowledge of pre-eclampsia and eclampsia in Bangladesh," Ending Eclampsia Brief. Washington, DC: Population Council. 


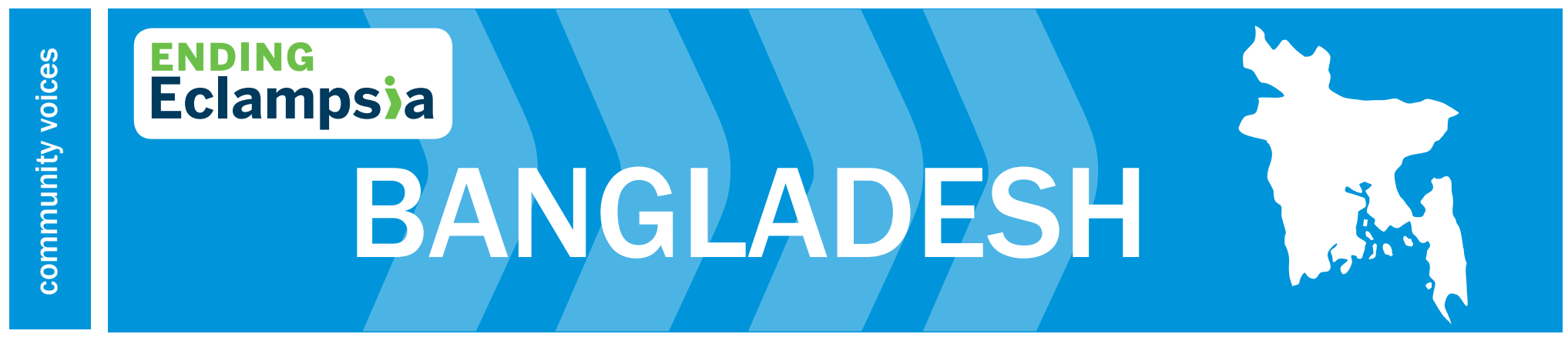

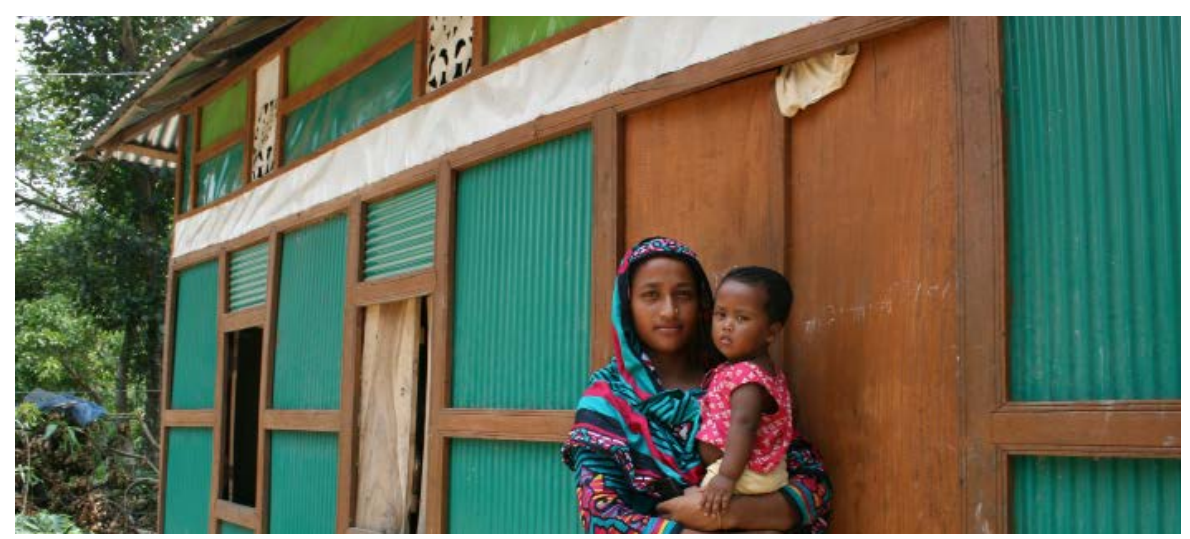

\section{KNOWLEDGE OF PRE-ECLAMPSIA AND ECLAMPSIA}

Over the last three decades, the social and economic status of women in Bangladesh has improved, but a vast majority of women are still dependent upon the decisions of their mothers-in-law and husbands on seeking health care outside of the home and visiting health providers.

In Bangladesh between 1,000 and 1,200 women die every year from pre-eclampsia and eclampsia ( $\mathrm{PE} / \mathrm{E})$, contributing to 20 percent of maternal deaths. It is the country's second leading direct cause of maternal mortality. In addition to the burden of maternal mortality, when a mother dies her baby is at increased risk of dying during the first year of life.

The etiology of PE/E remains unknown, and the disease pathways are not fully understood. What is clear is that death from PE/E is avoidable if the condition is detected during early antenatal care (ANC) visits and its progression to eclampsia is prevented. The World Health Organization recommends eight ANC visits, yet only 31 percent of pregnant women attend as many as four ANC visits. Barriers, including lack of awareness about signs and symptoms of PE/E, lack of access, financial hardship, and cultural norms cause delays in seeking timely care.

\section{RESEARCH}

To fully understand community perceptions of PE/E, the Population Council conducted a landscape analysis in 12 upazilas in four districts. The study included a desk review of published and unpublished resources about PE/E in Bangladesh; in-depth interviews (IDI) with policy makers, partners, program managers, $\mathrm{Ob} /$ Gyn professionals and primary care facility (PHC) service providers; focus group discussions (FGD) with married men and women; IDIs of women who experienced $\mathrm{PE} / \mathrm{E}$; observation of ANC consultation and exit interviews; and facilitybased inventories. This brief presents those research findings.

\section{Recommendations}

- Community awareness for ANC services, including information about PE/E, with public representatives, religious leaders, imams, priests, local government, health workers.

- Social behavior change materials should include information on the importance of ANC and PE/E.

- Mass media campaigns and interpersonal communications to target married men and mothers-in-law and promote health-seeking behaviors of pregnant women.

- Mass media campaigns and interpersonal communications share the signs, symptoms, and dangers of $\mathrm{PE} / \mathrm{E}$, the importance of antenatal care, and timely treatment of $\mathrm{PE} / \mathrm{E}$.
The Population Council conducts research and delivers solutions that improve lives around the world. Big ideas supported by evidence: It's our model for global change. popcouncil.org

(C) 2017 The Population Council, Inc
POPULATION COUNCIL

Ideas. Evidence. Impact. 


\section{FINDINGS}

Knowledge and perceptions of $P E / E$

To assess community PE/E awareness, beliefs, and experiences and strategies for seeking care, researchers investigated community perspectives in male and female FGDs and IDIs with PE/E survivors and their families.

Despite similarities, there were major disparities between female and male informants on the serious problems women can suffer during and after delivery.

Female participants said the most serious problems during pregnancy and following childbirth are excessive bleeding, convulsion, anemia, abdominal pain, physical weakness, malnutrition, retained placenta, ruptured uterus, and fetal presentation other than head first.

Male informants reported anemia, physical weakness, vaginal discharge, loss of appetite, headache, edema, retained placenta, and bleeding from the vagina as the most serious problems. Both men and women report that mothers-in-law are best equipped to determine when a women experiences complications.

"These are women's problems during pregnancy and after delivery. My mother also passed through

these. So, I don't want to interfere with women's problems and step in. My mother and grandmother might be the right persons to decide."

Male, FGD

"The mothers of our community think these are general problems during pregnancy and delivery and they also passed through these. So, they don't give much importance on the problems, rather suggest some spiritual and common sense remedies."

Female, FGD

Many beliefs and misconceptions about pregnancy-related complications, including PE/E, exist in these communities. Pregnant women are often prohibited from going outside, restricted to rigid diets, and many women are not allowed to use modern medicines during pregnancy and childbirth.

\section{Health-seeking behaviors during pregnancy}

The influence of mothers-in-law and husbands, financial solvency, perceptions about poor quality of care at hospitals, and lack of transportation negatively affect the health-seeking behaviors of women suffering from PE/E. These behaviors for pregnancy-related problems or com- plications follow a pattern: A pregnant woman who experiences convulsions is believed to be caught by "the evil eye." Mothers-in-law and husbands are the primary decision makers, and they first take pregnant women to the Imam or kabiraj, a traditional or spiritual healer. The next option is to visit a village doctor, as many believe "holy water," herbs, exorcism, and charmed amulets can improve problems in pregnancy. Only if her condition does not improve, then will she travel to a hospital or private clinic for health services.

"We go to the village doctors or kabiraj [traditional or spiritual healers] seeking health services because of finances and lack of good treatment in the government hospital. There is no good doctor in our hospital."

Female, FGD

Community members and pregnant women lack awareness and knowledge of PE/E danger signs, particularly high blood pressure. Many pregnant women are not even informed about danger signs during their ANC visits.

"My husband intends to take [me] to the hospital but my mother-in-law said that the nowadays daughters and daughters-in-law don't have faith in Allah. They think that when they gave birth they did not go to the doctor or hospital, so they don't want to take them to the hospital. They only take the women to the doctor when it is too late and the mother and child's condition become serious.

Female, FGD

Service providers and communities are uncertain of referral mechanisms. According to many pre-eclampsia survivors, they did not receive proper, timely, and adequate information and treatment at PHCs and were referred from one facility to another, in public and private facilities.

Stronger awareness of the importance of early ANC and of seeking care at facilities when women experience complications during pregnancy, specifically symptoms of $\mathrm{PE} / \mathrm{E}$, will empower women and their families and fewer deaths of women and babies will result from $\mathrm{PE} / \mathrm{E}$.

\section{FOR MORE INFORMATION}

Kanij Sultana at Ksultana@popcouncil.org, info@endingeclampsia.org For more information, visit www.endingeclampsia.org.

Citation: Warren, Charlotte, Sharif Hossain, Rahat Ara Nur, Kanij Sultana, Karen Kirk, Amy Dempsey. 2015. "Landscape Report on Pre-eclampsia and Eclampsia in Bangladesh." Washington, DC: Population Council. 